\title{
Perspectives of South African Special School Teachers on Special Schools as Resource Centers
}

\author{
Mbulaheni O Maguvhe (Ph.D.) \\ Associate Professor, University of South Africa \\ College of Educatio, Department of Inclusive Education \\ Tel: 012 429-4300 Email: maguvmo@unisa.ac.za
}

Doi:10.5901/mjss.2013.v4n14p711

\begin{abstract}
Introduction: Inclusive education has gained increased favor as a move towards more democratic regular classrooms, striving to deliver equal education to all who learn in them. Schools should, as much as possible, be able to teach a diversity of students in the same classroom. The key factor for instance buy-in is that, out of the estimated 505867 people with visual impairments in South Africa, many children with visual impairments would be absorbed in schools nearest to their home environments. The study gathered perceptions of teachers in schools for the blind on the envisaged role of special schools as resource centers that should help capacitate full-service schools. Methods: A qualitative research design study was carried out with eight interviewees (four males and four females): all teachers serving in six schools for the blind in three provinces (Limpopo, Free State and Mpumalanga). Results: Teachers need more ongoing training. There is a need for more resources to be allocated to special schools for them to find what to cascade to full-service schools. There is also a need for changing regulations governing the role of teachers in special schools as regards their new itinerant duties or responsibilities. Specialists want status or recognition that is tied to increased remuneration. Discussion: There seems to be a need for massive teacher development (re-skilling, reorientation and re-sensitization). There are persuading arguments for a government led drive to recapitalize special schools - cognizant of their proposed role as resource centers for full-service schools. The role of teachers in special schools should allow for duties in full-service schools. Implications for Practitioners: The collective picture of arguments put forward in the discussion is that ultimately, every school should have a strong team of teachers who see to the needs of their whole student population. External help should kick-start internal capacity for daily program continuity to be guaranteed.
\end{abstract}

Keywords: Inclusion. Resource centers. Full-service schools. Special schools. Support teams

\section{Introduction}

Inclusive education was born out of incremental modifications of different practices applied to the treatment of those who were perceived to be different in various societies. Over the centuries, the growth of human understanding particularly about causes of disability has helped to change human perceptions about disability and people with disabilities (Ashley, 1974:9). Growth in understanding and changes in treatment have not taken the same pace both within and across countries - although notable developments took place in the 1900s as a result of the disablement of war veterans of World War I (Szymanski \& Parker, 1996:1). Human understandings are shared (Underwood, 2012:106) - but they do not transform easily since they exist with complementary and intertwining attitudes. It is these 'understandings' that could either propel or stall the progress of various movements in education, including the management of the inclusive education campaign. Flem and Keller (2000:190) allude to the possibility of a plethora of interpretations for inclusive education policies and explain thus, "Both policies and practices are dependent on the values and ways of thinking of the participants involved." In like manner, the philosophy of inclusion in South Africa may not be understood by all stakeholders in a singular way, resulting in variations in micro-practice.

Government's plan to roll-out inclusive education is grounded on the unique and critical role that special schools have to assume as role-mentors to the first batch of inclusive schools, here-in-after termed full-service schools. According to Asmal (2004:10), the National Department of Education highlighted six key strategies and key movers for change towards inclusive education. These are: converting special schools into resource centers to support full-service schools together with district based personnel, returning many children who were out of school into the school system, designating an initial five hundred schools in thirty school districts into full-service schools, orientating and training key 
implementation partners on the inclusion model and early identification procedures, setting up positions of professional support service staff - and implementing a nation-wide advocacy and information campaign focused on roles, responsibilities and rights of schools and their cooperating partners (educators, parents and local communities). The author of this article focuses his attention on the first strategy because it is conceivably a king-pin in the implementation of the other five strategies.

The fact that special schools should serve as resource centers in the provision of inclusive education is not unique to South Africa. As cited by Moore (1999:175), Dyson and Gains (1993) proposed similar cluster-based roles for special schools in the United Kingdom. Further, resource centers should provide particular expertise and support, more especially professional support in curriculum and instruction to full-service schools. By implication, special schools are given due recognition as institutions holding valuable information and resources, including specialist educators. Matters of particular concern rotate around the training necessary for one to be considered a specialist teacher. In a research on 'The role of the support teacher in Australia', Forlin (2001:128) made a list of qualities which support teachers considered necessary for their role. There were presented as follows:

(i)be fully trained; (ii) be experienced teachers; (iii) have formal training in teaching students with special needs; (iv) be eligible for financial support for further training; (v) have their training acknowledged by increased status or remuneration.

The teachers whose opinions are quoted above had qualifications ranging from occasional training on roles they had to perform as support teachers, some form of further formal study, the majority had a diploma in the education of students with special needs (40 percent), others had a bachelor's degree in Education (Special Education) (25 percent). Sixteen percent of the sample had MEd (Special Education). Just 6 percent were 'currently' enrolled in an additional course.

There is reason to believe that characteristics of teachers are important in ensuring the successful facilitation of inclusive education processes (Flem \& Keller, 2000:198). Teachers with well defined baseline qualifications offer the benefit that they can carry out specifically defined duties. Such teachers could support the professional development of school staff (Forlin, 2001:128), run training workshops in district schools as part of the district support team (Department of Education, 2001:21) and assess students with special needs, write diagnostic reports, assist in the compilation of Individualized Education Programs (Flem \& Keller, 2000:197). The teacher should therefore be equipped with relevant skills (Lumadi \& Maguvhe, 2012:375). It would then be expected that a role description of such a teacher should be generated. Participants in the current research did not establish the qualifications of a teacher they considered as a specialist. Notwithstanding that definition gap, it makes sense that the perceptions of teachers be thoroughly understood, since they finally undertake daily duties to bring the inclusive education program to fruition. If their voices are heard, they could feel empowered and motivated to execute their mandate effectively.

This study explores some of those 'understandings' from the perspective of teachers in schools for the blind, particularly as they relate to the role of special schools as resource centers which should spearhead the development of inclusive education across the country. Although there is government documentation spelling out a national standpoint (Education White Paper VI of 2001) on inclusive education, there are pointers to a divergence of views among teachers in special schools. This paper examines the role envisaged for special schools as resource centers by analyzing what teachers in those schools view as their progress to-date. As an example, special schools should run training workshops for other educators; adapt and make learning materials available in accessible formats as well as the setting up of a district lending system to share such materials with other schools; and setting up a helpline for educators and parents. Cognizance should be taken that the above mentioned examples are just the tip of an iceberg since the supposed roles of specialist teachers extend to the establishment of school ethos, development partnerships and sensitization of various publics on learner diversity among other roles (Department of Education, 2001:23).

The central problem is that much as the planned execution of the inclusive education drive is excellent, the practical dimension is perceived by some important players as pace-discordant. There seems to be an outcry from teachers in special schools about developments on the ground. They hold the view that little seems to be taking place and something seems to be stalling the pace of the inclusive education drive in South Africa.

\section{Research Questions}

What does it mean to you that 'special schools should function as resource centers?'

Since your school is identified as one of the resource centers, is it ready to carry out its mandate?

What are the key challenges experienced by your school in performing its role as a resource center? 


\section{Research Methods}

The qualitative research design was employed for this study because of its flexibility to allow for the use of several methods. Qualitative methods assume that realities are socially constructed by individuals within a social context, and allow a variety of methods to be employed to collect data until a comprehensive understanding of the phenomenon under study is reached (McMillan \& Schumacher, 2010:23; Welman, Kruger \& Mitchell, 2005:152). Interviewees were selected using purposeful sampling due to the fact that only six out of the twenty-one schools for the blind have been identified as resource centers so far. Data were collected through semi-structured interviews involving four school management teams (a team comprising two members) from four schools that consented to participate in the research. Follow-up questions were also posed to elicit more information and clarifications. Follow-up telephone interviews were conducted to test and verify the information collected to ensure the accuracy of facts.

Participants in this study gave responses to research questions listed above. They were from four schools in three provinces: Limpopo, Free State and Mpumalanga.

To save time and traveling costs, the researcher decided to conduct the research while in those provinces for official duties. The interviews were conducted after official business hours - allowing both the interviewer and interviewees to conduct their official duties without disturbance. This arrangement did not compromise the quality of the research, since time was used efficiently.

\section{Composition of the Sample of Respondents}

Table 1

\begin{tabular}{|l|l|l|l|}
\hline Province & No. of Respondents & Male & Female \\
\hline Limpopo & 4 & 2 & 2 \\
\hline Mpumalanga & 2 & 1 & 1 \\
\hline Free State & 2 & 1 & 1 \\
\hline Total & 8 & 4 & 4 \\
\hline
\end{tabular}

\section{Ethical Considerations}

The author strictly followed ethical procedures to protect study participants from all types of violations of human rights, free wills, integrity, confidentiality and beneficence. Individual study participants gave verbal consent to their participation in the study, out of their own free will, in accordance with the principles of social research ethics and human rights.

\section{Findings}

\section{Question One:}

What does it mean to you that 'special schools should function as resource centers?'

The study revealed that:

- $\quad$ special schools should be coordinating centers for all full-service schools to carry out their mandate as schools that set an example on inclusive education.

- $\quad$ special schools as resource centers, are expected to be well staffed with specialists who would satisfy the demand for consultants by neighboring schools.

- teachers holding certificates and diplomas in special education considered themselves as specialists who should play a leading role in driving the inclusive education process.

\section{Question Two:}

Since your school is identified as one of the resource centers, is it ready to carry out its mandate?

The study revealed that:

- $\quad$ special schools for the blind are not yet ready to carry out their mandate as resource centers. Reasons given for their inability to carry out the mandate included, but were not limited to . fact that they are still underresourced 
- full-service schools have not started to enroll learners with visual impairments in a systematic, coordinated and holistic manner. In some districts, district-based support structures are either non-functional or nonexistent.

- teachers have not yet received in-service training on both specialist teaching areas and the process of including learners with visual impairments.

\section{Question Three:}

What are the key challenges experienced by your school in performing its role as a resource centre?

The study revealed that:

- $\quad$ the mindsets of some key personnel in special education have not changed from the singular belief in special schools, leading to a 'wait and see attitude' which stalls progress.

- There is no singular understanding of inclusive education in the country. This causes differences in the application of 'inclusivity'.

- Some powerful sectors of the public have not embraced inclusive education. Companies that should be engaged in corporate social responsibility in the area of inclusive education do not feel impelled to promote it.

\section{Discussion}

\section{Question One:}

What does it mean to you that 'special schools should function as resource centers?'

Pertaining to this question, it was revealed that special schools should play a critical role in coordinating all full-service schools in carrying out their mandate as exemplary schools in removing barriers to learning for all students. Thus, through that assistance, full-service schools would be able to create an inclusive, accessible and conducive learning environment. It was also the respondents' view that special schools have specialists who would satisfy neighboring schools' demand for consultants. Spungin \& Ferrell (2012: 1) consider that the specialist teacher for students with visual impairments could be the most important member in a support team for students with visual impairments. In support of the above argument, one respondent noted:

Many teachers in special schools hold certificates and diplomas in special education. This makes us specialists. Isn't it? We should be the ones who play a leading role in driving the inclusive education process.

Another respondent seemed to fine-tune the qualification of a specialist when she said:

We do not want novices to spearhead this campaign. Seasoned campaigners should champion the inclusive education cause. Seasoned campaigners to me are torch-bearers. They are real specialists.

Another respondent added:

In actual fact, the most qualified among teachers should be identified and promoted to district and provincial special education positions, where they would serve well as specialists. They would then be able to in-service teachers serving on school-based teams. Currently, district officials in the said positions do not address special needs matters. They come to address matters on grievance procedures, conflict resolution and other education administration processes. They are not special educationists - to put it simply.

These inputs show that there is a need for training in special needs education among different ranks of the education system in the country. Palmer, (1996), in an editorial to Conquest Magazine, implored managers to suppress pride and seek relevant education. Based on these engagements, the author of this article conclude that a perceived lack of specialists (and an imprecise definition thereof), especially among education administration officers, could be an underlying factor hampering the provision of high quality service for learners in full-service and ordinary schools.

\section{Question Two:}

Since your school is identified as one of the resource centers, is it ready to carry out its mandate?

What came out clearly was that special schools for the blind are not yet ready to carry out their mandate as resource centers. Factors contributing to this state of unpreparedness included, and were not limited to under-resourcing, fullservice schools not admitting learners with visual impairments in a systematic and coordinated manner and support structures that were non-functional or non-existent. Teachers also lamented what they viewed as a severe lack of in- 
service training on both specialist teaching areas and the process of including learners with visual impairments.

One respondent articulated the lack of preparedness thus:

Special schools are under-resourced. They do not have enough adapted books and specialized equipment to enhance teaching and learning, yet the powers that be consider them as affluent and able to support other schools. Without them being re-vitalized, special schools will become poorer by the day and lose the little ability they have to serve or satisfy their own needs.

Apart from the need to re-equip special schools for the daunting task, there is a need for training teachers in special schools. There seems to be a great need for transformational leadership for the success of the inclusive education drive. There also seems to be a great need for teacher efficacy on engagements that propel sustainable [inclusive] education (Lumadi, Maguvhe \& Dzapasi, 2012:292).

One respondent said:

Many people suppose that merely teaching at a school for the blind makes one a specialist teacher. Although there are specialists in schools for the blind, some teachers in special schools are not knowledgeable about crucial subjects that facilitate the education of learners with visual impairments. These teachers need intensive training so that special schools would indeed be nuclei of transformative capacity. Training could be given in subjects such as braille, orientation and mobility and skills of daily living.

The author of this article has picked up a recurring theme; that teachers see training as an area that needs urgent attention. In their view, every teacher at a special school should be a specialist who could contribute to the diverse needs of full-service schools. The base-line qualification for one to be considered as a specialist is not clarified by the teachers' contributions.

\section{Question Three:}

What are the key challenges experienced by your school in performing its role as a resource centre?

Responses gathered on this question highlighted that there were a myriad challenges experienced by special schools in their quest to perform their role as resource centers. This dilemma could be attributed to the mindset of some key personnel in special education administration which have not changed from the singular belief in special schools, thus leading to a 'wait-and-see' attitude - thus stalling progress.

One respondent expressed her conviction that some authorities still held the view that special schools were incapable of offering help to regular schools:

The problem with some old-fashioned personnel in decision-making positions is that they do not actually believe that special schools are able to play a consultancy role. They believe that special schools are themselves in need of help so that they become 'normal.' This kind of attitude stems from the medical model. It is a demonstration of ignorance about the positive outlook brought about by the social model. It actually thwarts the impetus of the inclusive education drive.

Furthermore, the fact that there is no singular understanding of inclusive education in the country leads to different interpretations and variations in implementation strategies; culminating into major differences in the application of 'inclusivity.'

Explaining the divergence of views that people hold about inclusion, one respondent said:

The problem is that while I think inclusion is about learners attending school in the same class and receiving information in ways that suit each individual most, some teachers believe that a special class in a regular school is also inclusive. It looks as if there are as many interpretations of inclusion as there are teachers in our schools.

Another respondent saw inclusion as follows:

My take on inclusion is that it is a system that promotes effective learning among all learners. For me, government should show real commitment to set up and support this initiative in real terms. Furthermore, learners have the right to access the educational support needed to develop to their maximum potential. In a nutshell, inclusion should guarantee equal access to formal schooling.

The respondent continued:

What is happening is that some learners are deliberately 'uprooted' from their parent special schools, only to be taught by teachers who do not know intervention strategies necessary to benefit the learners academically. It is pathetic to consider that in some cases the schools could still seek help from district and provincial education support systems only to find no attendant specialist in visual impairments. Structures need to be established solidly I tell you. 
The problem which inclusive schools find in sourcing external help seems to be wide-spread since Pijl and Van Den Bos (2001:118) also quote a support coordinator in The Netherlands thus, 'The external support is so minimal that it is not worth talking about' - with reference to the rate at which regular schools obtained help from specialist personnel outside the school. They further observed that many schools had reported a 30 percent support rate annually. This could mean that even when South African special schools assume their active role as resource centers, full-service schools may not have to expect miracles in terms of the amount of help they will get. There would still be a need for the full-service schools to build their own internal resources to meet most of their teaching needs. There should therefore be genuine systemic and school-based preparation for the accommodation of the learning needs of every student (Lumadi, Maguvhe \& Dzapasi, 2012:298).

A condensed observation was given by one respondent who viewed problems in kick-starting inclusive education as primarily based on a single cause. She said:

The problems bedeviling inclusive education today are basically financial. Some powerful sectors of the public and private domain have not embraced inclusive education. They have disengaged from their erstwhile corporate social responsibility in special education. They seem not to see the need to support and promote inclusive education.

Unless the popular mindset on special needs provision shifts drastically, and people share a workable definition of inclusive education, it will be difficult to obtain adequate funding for inclusive education.

\section{Implications for practice}

\section{Question 1}

Special schools should be given the means to play a true coordinating role for all full-service schools so that they in turn fulfill their role on inclusion efficiently. Furthermore teachers in existing special schools should receive rigorous specialist training so that they fulfill consultancy roles needed by full-service schools. Lastly, the Department of Basic Education (from the circuit to province) should make provision to allow teachers in special schools to play a meaningful role in driving the inclusive education process - this could mean employing them in various positions across the education service.

\section{Question 2}

To prepare special schools to carryout their mandate as resource centers, there is need to equip them in terms of learner teacher support material (LTSM) to enhance learning - that needs funding. In addition, there should be a monitoring and evaluation body which sees to the viability of special education functions. Such a body could be made up of independent persons, specialists from government and specialist teachers. In terms of training, a thorough human development program should be in place. That requires an annual budget for staff development.

\section{Question 3}

To establish a unified view and purpose of inclusive education, there is need to institute a relentless sensitization and advocacy campaign which covers all levels from schools to provincial personnel. There is a need to establish partnerships between public, non-governmental and private sectors so as to promote constructive engagement on matters around education in general and inclusive education in particular.

\section{Conclusion}

The effectiveness of resource centers lies in the volition of all stakeholders to take charge of inclusive education processes. This begins with efforts to establish a common liking for the concept of educational inclusion (a nationwide buy-in of the concept of inclusion). The Department of Basic Education should always strive to show a commitment to the provision of inclusive education through establishing proper budgetary mechanisms. It would also be important to use specialists in various special schools to the optimum, for full-service schools to thrive in their mandate as beacons for the rest of regular schools. 


\section{References}

Ashley, J. (1974). Foreword. In R. Bleackley (Ed.), Despite Disability: career achievement by handicapped people. (pp. 9-10). Reading: Educational Explorers.

Asmal, K. (2004). Inclusive Education and Training Booklet. Pretoria: Department of Education.

Department of Education. (2001). Education White Paper 6. Special Needs Education: Building an Inclusive Education and Training System. Pretoria: Department of Education.

Flem, A. and Keller, C. (2000). Inclusion in Norway: a study of ideology in practice. European Journal of Special Needs Education. 15(2): 188-205.

Forlin, C. (2001). The role of the support teacher in Australia. European Journal of Special Needs Education. 16(2): $121-131$.

Lumadi, M.W. \& Maguvhe, M.O. (2012). Teaching Life Sciences to Blind and Visually Impaired Learners: Issues to Consider for Effective Learning Mediation Practice. Anthropologist. 14(5): 375-381.

Lumadi, M.W., Maguvhe, M.O. \& Dzapasi, A. (2012). Transformational Efficacy of a Curriculum for People with Visual Impairments. Anthropologist. 14(4): 291-303.

McMillan, J.H. and Schumacher, S. (2010). Research in Education: Evidence-Based Inquiry (7th Ed). Boston: Pearson.

Moore, J. (1999). Developing a local authority response to inclusion. Support for Learning. 14(4): 174-178.

Palmer, D. (1996). Editorial: The challenge for our leadership in 1996. Conquest, 8(1): 1.

Pijl, S.J. and Van Den Bos, K. (2001). Redesigning regular education support in The Netherlands. European Journal of Special Needs Education. 16(2): 111-119.

Szymanski E.M. and Parker, R.M. (1996). Work and Disability:Introduction. In E.M. Syzmanski and R.M. Parker (Eds), Work and Disability: Issues and Strategies in Career Development and Job Placement (pp. 1-7).Texas: Pro-ed.

Underwood, C. (2012). Belief and attitude change in the context of human development. In I. Serageldin (Ed), Sustainable human development in the twenty-first century - Vol. II (pp. 103-124). Paris: UNESCO.

Welman C, Kruger F, Mitchell B (2005). Research Methodology (3rd Ed). Cape Town: Oxford University Press Southern Africa. 
